\title{
Produzindo um pôster científico
}

\author{
Carlos Umberto Pereira', Débora Moura da Paixão Oliveira² \\ Serviço de Neurocirurgia do Hospital Governador João Alves Filho, Universidade Federal de Sergipe, SE, Brasil \\ Trabalho apresentado no XXVI Congresso Brasileiro de Neurocirurgia, Florianópolis, SC, setembro de 2006
}

\begin{abstract}
RESUMO
Objetivo: Demonstrar como organizar as informações de modo que as idéias centrais de trabalhos científicos na forma pôster sejam facilmente apreendidas, bem como orientar a utilizar os recursos disponíveis para o pôster despertar o interesse do público. Apresentações no formato pôster tornam-se uma parte cada vez mais importante de conferências científicas, são excelentes para apresentadores iniciantes por ser consideradas menos desafiadoras do que as apresentações orais.

Um pôster bem desenhado dá ao público uma vista geral e concisa de pesquisa, metodologia, tamanho da amostra, resultados e suas implicações, por isso requer o esforço considerável em identificar os ingredientes vitais e rejeitar todo o material supérfluo.

\section{PALAVRAS-CHAVE}

Comunicação científica. Pôster.

\section{ABSTRACT}

Creating a scientific poster

Objective: Show the guidelines to create an effective poster presentation for scientific information. Poster presentations have been taking an important part of scientific meetings, are well shaped for beginning authors as is less challenging than the oral presentations. Well drawn posters give to the public a general and concise sight of the research, methodology, size of the sample, results, and its implications. Therefore it requires a considerable effort in identifying the vital ingredients and rejecting all the superfluous informations.
\end{abstract}

\section{KEY WORDS}

Scientific communication. Posters.

\section{Introdução}

As sessões de pôster também chamadas de poster session são usadas freqüentemente em reuniões científicas na medicina, enfermagem e entre outras profissões da área de saúde para comunicar e indicar resultados de pesquisa científica. São meios eficazes de comunicar uma mensagem simples, compartilhar os resultados de uma pesquisa e estimular a discussão em uma atmosfera tranqüila. São também indicadas em empresas para facilitar uma comunicação interna sobre um projeto ou demonstrar as realizações conseguidas ${ }^{29}$.

A palavra pôster ou painel significa cartaz publicitário. A literatura relata que, na história da humanidade, foram os gregos e romanos que iniciaram a utilização de pôsteres nas ruas e praças com a finalidade de satirizar a monarquia e os clérigos. A partir dos anos 1800, os pôsteres passaram a ser coloridos e, na Idade Média, eram usados na divulgação da arte ou publicidade de artistas. Durante as guerras mundiais, foram utilizados para promover o recrutamento de soldados e voluntários, bem como para expor as atrocidades das guerras $^{15,24}$.

Segundo Butz e cols. ${ }^{1}$, os pôsteres foram introduzidos às reuniões científicas nos Estados Unidos durante os anos 70 . Johns ${ }^{16}$ relata que a primeira referência encontrada na literatura a respeito do pôster científico data de 1976. Os painéis científicos foram criados em virtude do grande número de sessões simultâneas que dificultava ou impossibilitava os participantes de assistirem às apresentações de interesse comum, bem como o número insuficiente de salas para atender à 
grande demanda de trabalhos científicos apresentados na forma oral. As sessões pôsteres foram criadas para atenuar o grande número de rejeições de trabalhos que ocorria em virtude da falta de espaço nas salas de reuniões, bem como pela possibilidade de aumentar o número dos estudos que poderiam ser apresentados simultaneamente ${ }^{1,5}$.

No princípio, os painéis eram esquecidos em corredores de eventos e não eram considerados importantes; atualmente, tornaram-se parte significante de conferências regionais, nacionais e internacionais ${ }^{5,22}$.

\section{Pôster ou apresentação oral?}

A disseminação do conhecimento é um dever fundamental em toda disciplina, e cada vez mais os cientistas são requeridos a comunicar os resultados de suas realizações clínicas ou teóricas. No entanto, alguns pesquisadores se indagam sobre qual a melhor maneira de apresentar tais resultados. Shelledy ${ }^{25}$ relatou que a apresentação de uma pesquisa na forma pôster é uma etapa útil, antes de publicá-la em um jornal respeitado da ciência. Outros autores ${ }^{9,14}$ consideram importante ganhar um prêmio de melhor trabalho apresentado em um congresso no modelo pôster, uma vez que, segundo Karamzadeh e cols. ${ }^{17}$, os pôsteres produzem o mesmo impacto científico quando comparados com as apresentações orais.

Vários autores ${ }^{3,4,18,20}$ acreditam que a estratégia de apresentação em formato painel é uma maneira eficaz de apresentar a informação com uma aproximação interativa, atrai audiência, interage e esclarece o processo da pesquisa, permite a expressão criativa na apresentação e ajuda a construir relacionamentos com outros que possuem interesses similares. Outros autores ${ }^{4,9,24,27} \mathrm{pu}-$ blicaram que as apresentações de pôster são excelentes para iniciantes, pois intimidam menos do que apresentações orais; uma vez que se usa mais o recurso visual, a audiência é freqüente, porém o público comparece um a um, fazendo a discussão fluir prontamente.

Butz e cols. ${ }^{1}$ mencionam que a desvantagem do pôster é a possibilidade de ser ignorado caso seja mal confeccionado, o que não é possível em uma apresentação oral.

Tulsky e Kouides ${ }^{28}$, embora julguem que as apresentações de pôster tenham um papel importante, pois oferecem troca de informações, propostas colaborativas e críticas construtivas, sugerem que cerca de $65 \%$ dos congressistas preferem apresentar sua pesquisa em formato oral, uma vez que se tornam visíveis nacional ou internacionalmente. Uma desvantagem das apresentações orais é a limitação do tempo concedido, em geral, de apenas dez minutos ${ }^{5}$. Entretanto, Campbell ${ }^{2}$ acredita que, para muitas pessoas, o discurso público induz o estresse e o medo.

Apesar das divergências ideológicas entre as apresentações orais e em painéis, sabe-se que, graças à computação e aos avanços tecnológicos da informática, os pôsteres transformaram-se em um instrumento de eleição para comunicar a informação científica a uma grande audiência ${ }^{20}$. Contudo, apesar de ser uma prática muito utilizada como meio de comunicar achados atuais de pesquisas médicas e práticas inovadoras de cuidados de enfermagem, muitos pesquisadores ainda consideram difícil a sua apresentação por terem dúvidas em relação à metodologia da confecção.

\section{Organização de pôster}

Um pôster é a compreensão visual do que se deseja indicar. Sua finalidade é esboçar uma parte do trabalho em um formulário que facilite a assimilação, estimulando o interesse e a discussão, com objetivo final de troca de idéias entre o apresentador e o público que o $\hat{1}^{5,9,24}$.

$\mathrm{O}$ relato sobre experiências pessoais dos apresentadores de painéis que possam ajudar outros a prepará-los e apresentá-los eficientemente é considerado pequeno ${ }^{22}$. Apesar da grande utilização, ainda não foi dada, à sua preparação, a atenção que merece, e muitos pesquisadores são inexperientes em sua confecção e apresentação $0^{3,16}$.

Segundo a literatura, somente com planejamento, prática e compreensão adequados podem-se desenvolver apresentações que comunicarão a pesquisa clara e sucintamente, com um comportamento profissional e confiável. Assim sendo, antes de desenvolver uma apresentação em formato pôster, deve-se considerar a elaboração de um planejamento cuidadoso ${ }^{2,4,16}$.

Um pôster bem desenhado dá, ao público, uma vista geral concisa da pesquisa, da metodologia, da amostra, dos resultados e das suas implicações. Por isso, requer o esforço considerável em identificar os ingredientes vitais e rejeitar todo o material supérfluo ${ }^{29}$. A apresentação de pôsteres abarrotados de dados e difíceis de serem lidos é, segundo a literatura, considerada ignorância e arrogância ${ }^{5}$.

De maneira geral, os pôsteres são avaliados com base em cinco critérios: atrativo visual, qualidade da informação, relevância, originalidade e conteúdo de texto, gráficos e ilustrações ${ }^{29}$.

Para muitos autores ${ }^{5,7,14}$, um pôster conta uma história, portanto deve seguir uma seqüência lógica. Uma apresentação típica de pôster segue o mesmo formato de um artigo científico. White e White ${ }^{29}$ consideram 
que os tópicos apropriados para um pôster incluem experimentações clínicas, exames, estudos qualitativo ou quantitativo e relatos de caso. Embora as exigências possam diferir, algumas diretrizes ${ }^{1,16,18,23}$ demonstram que os pôsteres incluem geralmente os seguintes componentes: título, sumário, introdução, materiais e métodos, resultados, discussão, conclusões, tabelas, figuras e a literatura pesquisada.

Hammarling e Higham ${ }^{14}$ consideraram, em seus estudos, que uma apresentação científica deve incluir somente a indicação de um problema, a descrição do método de ataque, a apresentação dos resultados e um sumário do trabalho. A apresentação deverá ter um máximo de atrativo informativo, porém evitar a desordem. Franzolim ${ }^{8}$, em 2004, chamou a atenção para o fato de que a escrita deve ser clara à primeira leitura e recomendou ao pesquisador não escrever palavras a mais do que o necessário, uma vez que nem o pesquisador, nem o leitor tem tempo para o que é excessivo. $\mathrm{Na}$ opinião de $\mathrm{Secaf}^{24}$, um pôster deve ser completo, mas conciso, para que o leitor não gaste mais de cinco minutos para lê-lo.

Day $^{5}$ publicou que o preenchimento excessivo afasta as pessoas, considerando importante a existência de espaço em branco na apresentação. Um leitor típico pode gastar somente alguns minutos para olhar um painel, o seu trabalho será um de muitos na área de exibição, assim é necessário certificar-se de que o pôster capturará e prenderá a atenção do leitor ${ }^{14}$.

Briscoe (apud $\mathrm{Day}^{5}$ ) afirmou que é preciso brilhantismo para condensar e focalizar informação em uma apresentação simples e clara para ser lida e lembrada.

\section{Título}

Gusmão e Silveira ${ }^{11}$, em publicação de 2001 sobre o mesmo tema, considerou que o título é o rótulo que identifica o conteúdo do trabalho, sugerindo aos pesquisadores que escolha um título que identifique a pesquisa; que opte por um título que, mesmo sem a leitura do resumo, o leitor possa identificar sobre a que tema está relacionado o trabalho. Secaf ${ }^{24}$, em suas publicações, relatou que poucos congressistas lêem o artigo inteiro, porém muitos lerão o título da pesquisa. Escolha um título claro que atraia a atenção do leitor.

O número de palavras recomendado para um título pela American Psychological Association ( $a p u d \mathrm{Secaf}^{24}$ ) varia entre dez e 12. Entretanto, Secaf ${ }^{24}$ considera de fundamental importância que um título não possua mais de sete palavras e recomenda que o pesquisador use a palavra menos difícil e mais esclarecedora.

Evite usar gíria, neologismo, abreviaturas, siglas, nomes comerciais e fórmulas químicas. Também não é aconselhável utilizar o tempo verbal gerúndio ${ }^{24}$.
O tipo de fonte escolhida deve ser facilmente legível por uma pessoa que está a alguns metros afastada. Alguns autores concordam que o título do trabalho deve ser legível a uma distância que varia de $1 \mathrm{~m}$ a $1,20 \mathrm{~m}^{19}$; outros sugerem que possa ser lido a até $3 \mathrm{~m}$ de distância $^{5}$. Entretanto, todos são unânimes em afirmar que o título deve ser curto e atrativo ${ }^{1,5,9,11,24}$.

É recomendado usar fonte Arial ou Times New Roman com cerca de $3 \mathrm{~cm}$ de altura, entre 60 e 92 pontos, em negrito e caixa alta; não se usa ponto-final ${ }^{5,9,26,24}$. Os nomes dos autores devem estar próximos ao título com letras pouco menores, cerca de $2,5 \mathrm{~cm}$ de altura, entre 48 e 72 pontos, incluindo suas afiliações e instituições; o grau acadêmico dos autores pode ser omitido. Usar letras maiúsculas e minúsculas ${ }^{9,26}$

O bom uso da cor deve ser feito para fornecer uma imagem mais interessante. Há abundância de espaço para a criatividade, porém evite o exagero ${ }^{10}$.

\section{Sumário}

É a apresentação sintética dos pontos relevantes do trabalho. Tem como objetivo fornecer uma visão panorâmica do conteúdo da pesquisa. Deve começar com a definição do problema, seguida de uma justificativa do trabalho, o objetivo, uma indicação simples da finalidade da pesquisa, o método utilizado, o relato de forma concisa do que foi encontrado e quais as suas implicações ${ }^{11,12}$. Porém, para isso, não é necessário escrever em sentenças completas; os fragmentos da sentença podem ser mais fáceis de compreender ${ }^{5}$. Butz e cols. ${ }^{1}$ chamam a atenção ao fato de que um sumário conciso captura o interesse das pessoas e as motiva a continuar lendo o pôster.

Se for necessária a versão do sumário em uma língua estrangeira, recorra ao serviço de um especialista?.

\section{Introdução}

É a apresentação sintética do problema. Ela informa por que a pesquisa é importante, fornece a razão para conduzi-la, justifica os objetivos e esclarece as questões a que pretende responder ${ }^{1,11,19}$.

Deve ser concisa e clara, focalizando os pontos principais, empregando o menor número possível de palavras para exprimir o pensamento, tornando o texto facilmente compreensível. Para alcançar concisão, devem-se excluir pormenores insignificantes, características irrelevantes e eliminar palavras ou adjetivos inúteis. Para isso, usam-se frases curtas, na ordem direta e opta-se pela palavra mais simples que defina a coisa ou a situação referida. Evite usar abreviaturas, acrônimos e jargão. É importante corrigir erros de gramática, pontuação e ortografia ${ }^{1,11,19,24}$. 


\section{Materiais e métodos}

Esta seção inclui as variáveis do estudo, apresenta com clareza o processo de coleta de dados, seleção e tamanho da amostra, instrumentos e meios usados para a coleta de dados, descrição da intervenção; deverá ser descrito de forma clara e objetiva, ser breve e conter uma a duas sentenças para descrever o tipo de abordagem usada ${ }^{1,5,11,12}$.

\section{Resultados}

Para alguns autores ${ }^{5,12}$, o resultado é considerado a parte mais importante da pesquisa. Os dados apresentados devem ser suficientes e claros. Comece com uma descrição sucinta da amostra, incluindo idade, raça ou etnia, instrução, status socioeconômico etc. Apresente os resultados que respondam à pergunta da pesquisa ou forneçam a solução ao problema.

A literatura é unânime em orientar os pesquisadores a usar pouco texto e mais ilustração para apresentar os resultados de um trabalho ${ }^{1,5,11,14,25}$. Apresentar visualmente dados em vez de incluir grandes quantidades do texto é incentivado usando-se figuras, gráficos e tabelas. Em 2004, Butz e cols. ${ }^{1}$ mencionaram que a maioria das pessoas recorda imagens melhor do que palavras. Muitos observadores lêem o título, fazem a varredura das imagens e das tabelas sem a leitura de qualquer coisa; entretanto, o número de tabelas e figuras deve ser apenas o suficiente.

Os gráficos legíveis e figuras são mais apropriados do que tabelas para apresentar resultados em um pôster. Tabelas são mais apropriadas em uma publicação ${ }^{7}$. Entretanto, não use tabelas, gráficos e figuras para quantidades pequenas de dados que poderiam ser apresentados clara e sucintamente em uma sentença. Também, não retrate nas sentenças os dados que são mostrados em uma tabela, gráfico ou figura. Durbin ${ }^{7}$ chama a atenção para que não se repita informação descrita em sentença em uma tabela, gráfico ou figura e sugere que, ao criá-la, deve-se eliminar a sentença do manuscrito.

Para um pôster, caso seja imprescindível usar tabelas, às vezes, é útil quebrar uma tabela grande em diversas menores para permitir que o leitor identifique facilmente a informação importante ${ }^{7}$.As tabelas devem ser auto-explicativas para que o leitor não tenha que recorrer ao texto para entendê-las ${ }^{11,13}$. Os títulos das tabelas devem ser curtos, claros e informativos e são geralmente colocados na parte superior e, os das figuras, na parte inferior ${ }^{11,13}$.

É aconselhável usar somente um tipo de fonte em tabelas, gráficos ou figuras. Geralmente, não se usa fonte em negrito, itálico ou colorida, a menos que o dado apresentado necessite destaque onde esses efeitos melhorarão a legibilidade, o que é considerado raro ${ }^{7,21}$.

Quando possível, use gráficos coloridos para apresentar resultados; entretanto, evite exagero de cores diversas, gráficos com muitas linhas, barras ou outras apresentações que dificultem seu entendimento. As legendas devem ser mínimas ${ }^{1,10,13}$.

\section{Discussão}

Deve ser embasada pelos dados da seção dos resultados. Compare os resultados obtidos na pesquisa com os de outros autores; exponha as aplicações práticas do trabalho; apresente possíveis limitações se existirem. As interpretações do pesquisador devem demonstrar um avanço no conhecimento ${ }^{1,11}$.

\section{Conclusões}

São deduções lógicas baseadas e fundamentadas no texto de forma resumida. Portanto, conforme ressaltado anteriormente, as conclusões devem ser breves, fornecendo ao leitor uma mensagem clara e pertinente; devem estar baseadas nos objetivos, ser coerentes com o método e estar de acordo com os resultados, não cabendo qualquer conclusão a que se tenha chegado pelo estudo da literatura ou pela experiência pessoal do autor ${ }^{12,19}$.

Podem ser descritas na forma de sentenças curtas numeradas. Admite-se fazer recomendações e sugestões de possíveis aplicações e de outras pesquisas subseqüentes ${ }^{5,12}$.

$\mathrm{O}$ apresentador pode sempre comunicar os pontos específicos aos participantes interessados. Entretanto, vale ressaltar que o pôster deve ser auto-explicativo - o autor não deve gastar a maior parte do tempo explicando-o em vez de responder às questões científicas; se isso ocorrer, o pôster não é bom ${ }^{5}$.

\section{Literatura pesquisada}

A inclusão de referências bibliográficas é opcional para a maioria das apresentações em formato pôster; deve-se citar o mínimo possível aquelas que focalizam dados relevantes à pesquisa ${ }^{1,5}$. Observe se as referências são pertinentes e atualizadas para o tema e se o período que abrange é suficiente. É importante citar trabalhos da literatura nacional ${ }^{12}$.

A seção das referências, quando necessário, é incluída geralmente no rodapé direito ou esquerdo, usando-se uma fonte de tamanho menor ${ }^{1}$. Seguem as normas da Associação Brasileira de Normas Técnicas (ABNT) em ordem alfabética do sobrenome do primeiro autor, 
a seguir o sobrenome e iniciais dos co-autores. Se a referência for citada no texto e tiver até três autores, colocar os três; quando a quantidade de autores for superior a três, deverá ser citado apenas o sobrenome do primeiro autor e acrescentada a palavra et al. ${ }^{13}$.

\section{Reconhecimentos}

Não é seção obrigatória. Alguns autores usam essa seção para agradecer assistentes de pesquisa, fontes de financiamento e as contribuições, porém não é necessário incluir cada componente, devido às restrições no tamanho do pôster. $\mathrm{O}$ apresentador pode incluir o mais relevante dos componentes para ajudar o leitor a compreender o projeto. Às vezes, dois componentes podem ser incluídos ${ }^{1}$.

\section{Confecção do pôster}

Hammarling e Higham ${ }^{14}$ consideram que a simplicidade é a chave na preparação de um painel. Assim sendo, não deve conter muitos detalhes. Os detalhes técnicos da produção do pôster incluem decisões sobre recursos humanos necessários, em que material será confeccionado, tamanho, fonte, cor, método para imprimir, material para prendê-lo e o transporte ${ }^{20,21}$.

\section{Material}

A impressão pode ser simples, elaborada na forma artesanal em papel A4, linho ou cuchê no modo paisagem em folhas avulsas com recursos domésticos de informática (figura 1), ou tipo banner, impressos por profissionais de artes gráficas em equipamentos especiais do tipo plotter (figura 2). O banner pode ser confeccionado com diversos materiais, desde papel sulfite até papéis especiais, plastificados ou laminados ${ }^{9}$.

Dê preferência para a impressão em uma folha matriz na vertical, embora outras possibilidades devam ser consideradas. A página em posição horizontal é menos confortável para o leitor, que tem de se mover para o lado; se houver muitos leitores, pode resultar congestionamento ao longo do pôster ${ }^{19}$.

Se houver alguma dúvida sobre a ordem em que o texto deve ser lido, guie o leitor, numerando o texto claramente ou ligando-o com setas. O fluxo da informação deverá ser lido seguindo a seqüência da esquerda para a direita e do alto para baixo ${ }^{1}$.

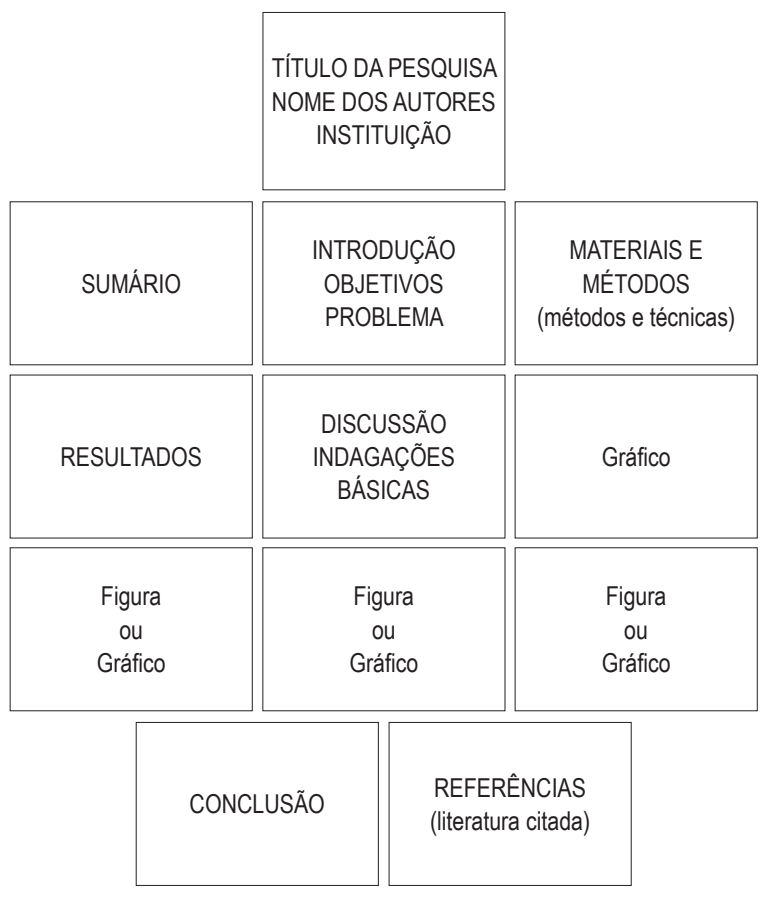

Figura 1 - Painel artesanal $\left(1 \mathrm{~m}^{2}\right)$.

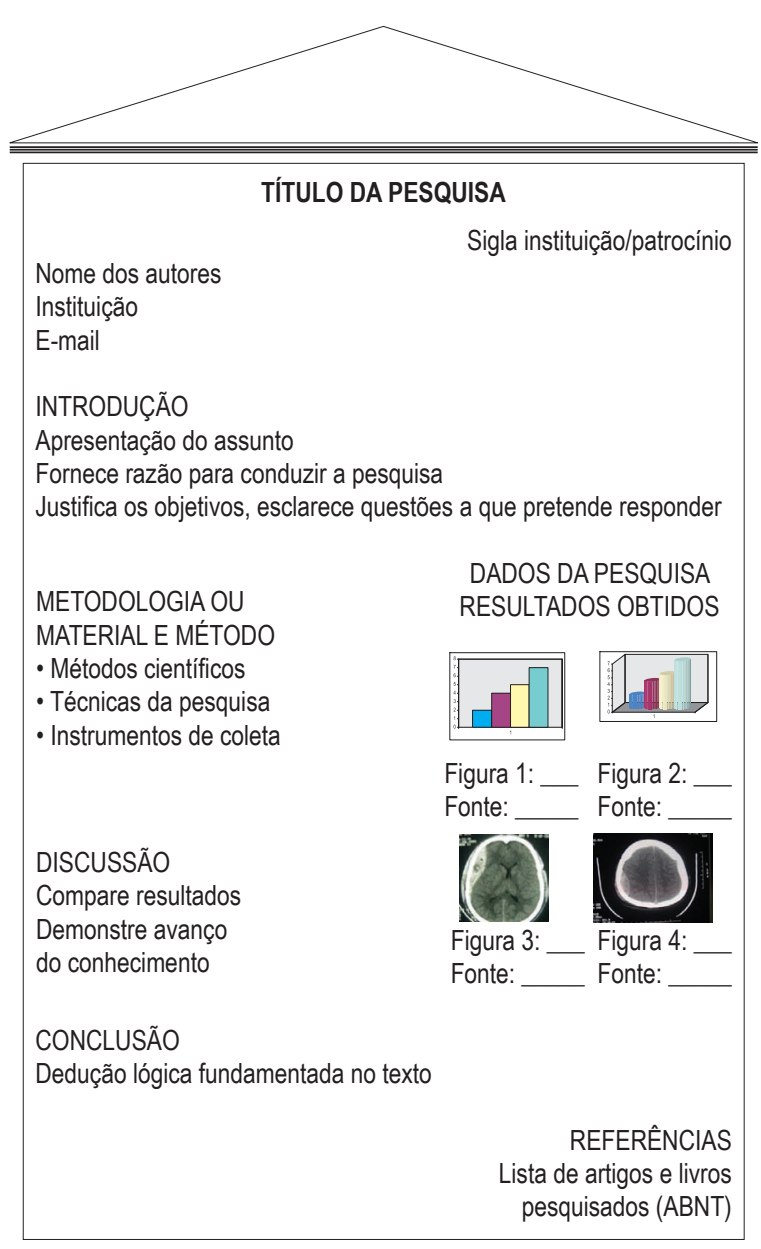

Figura 2-Banner. 


\section{Tamanho}

O tamanho da placa em que será colocado o pôster varia de acordo com a organização do congresso ou evento. Porém, as medidas mais recomendadas para a placa variam de $1,00 \mathrm{~m} \times 1,20 \mathrm{~m}, 0,90 \mathrm{~m} \times 1,20 \mathrm{~m}$ ou 1,20 m x 1,50 m,14,26. É aconselhável verificar, de antemão, o tamanho das placas que estarão disponíveis no evento. Gonçalves ${ }^{9}$ explica que 12 folhas de papel A4 equivalem a $1 \mathrm{~m}^{2}$. Pense com cuidado sobre o uso da placa, posicionando a folha a uma altura em que possa ser lida confortavelmente tanto por pessoas de baixa estatura como por pessoas altas ${ }^{21}$.

\section{Fixação}

Os métodos de fixação com pinos, prendedores ou velcro são fornecidos geralmente pelos patrocinadores do evento. Entretanto, é prudente levar o material adequado para fixá-lo em quantidade além do necessário para suprir qualquer eventualidade, muito embora a maioria dos banners já seja confeccionada contendo um cordão que facilita a fixação $0^{1,9,23}$.

\section{Fonte}

Escolha uma fonte fácil de ler; dê preferência a Arial ou Times New Roman e use a mesma fonte em todo o pôster. A fonte em itálico é de difícil leitura ${ }^{1,26}$. $O$ texto deve ser formatado em espaço duplo e justificado. O tamanho mínimo da fonte para o texto é 36 pontos $^{26}$.

\section{Cor}

A cor do texto é extremamente importante; a cor pode ser usada para atrair a atenção, porém o uso demasiado da cor distrai ou confunde. González-Tortosa ${ }^{10}$ é da opinião de que uma apresentação científica não necessita de tanta diversidade de cores e sugere o uso de até três combinações. O mais recomendado é o texto preto no fundo claro, já o texto branco em um fundo escuro é freqüentemente difícil de ser lido. Dê preferência às cores em tom pastel ou cinza claro ${ }^{1,21,26}$. Para os gráficos e elementos fotográficos, as cores brilhantes contrastando podem ser usadas ${ }^{10}$.

\section{Transporte}

O transporte do pôster pode ser um problema se este contiver folhas de papel grandes. Enrolar o papel em um cilindro é o sistema de escolha; entretanto, alguns congressistas ainda preferem a confecção artesanal em folhas avulsas por considerarem de transporte mais fácil. Caso utilize folhas avulsas para montagem no local, é necessário fazer um diagrama para evitar erro na colagem das folhas ${ }^{1,9}$.

Gonçalves ${ }^{9}$ recomenda que, em caso de viagem, não se coloque o material na bagagem a ser despachada; deve-se levá-lo na bagagem de mão. Em caso de extravio de bagagem, tenha sempre em mãos uma cópia do trabalho, em arquivo digital, que possa ser impressa em uma situação de emergência ${ }^{26}$.

\section{Custo}

Karamzadeh e cols. ${ }^{17}$ analisaram o custo-benefício na produção convencional de um pôster usando centros reprográficos de universidades e comerciais a baixo custo. Utilizando uma técnica simples, verificaram uma economia de até $95 \%$ do valor da confecção convencional.

Alguns congressistas preferem recorrer aos serviços de especialista em artes gráficas; todavia, vale lembrar que isso acarretará em um maior custo ${ }^{5,9}$. Os pôsteres podem ser consumidores de tempo e caros a menos que o cuidado adequado seja tomado nos estágios de planejamento. Com planejamento adequado e gabarito extensivo, um pôster pode ser uma apresentação recompensadora ${ }^{4}$.

\section{Apresentando o trabalho}

Alguns autores ${ }^{1,9,24}$ sugerem que o apresentador se vista apropriadamente de acordo com a temperatura do ambiente e recomenda o uso de sapatos confortáveis. É de fundamental importância certificar-se do dia e da hora para a montagem e desmontagem do pôster ${ }^{1,9}$.

Uma vez que a sessão começa, o apresentador deverá manter-se próximo ao trabalho, mas não em uma posição obscura. O tempo apropriado para a apresentação varia entre 12 e 15 minutos, e geralmente é mencionado no programa do evento e deve ser respeitado ${ }^{1}$.

A apresentação do pôster é proposta para representar uma exposição atraente da pesquisa; não é simplesmente $o$ ato de colar um artigo científico em uma placa. $\mathrm{O}$ apresentador deve estar pronto para responder às perguntas que, inevitavelmente, um bom pôster gerará; discutir detalhadamente os métodos e resultados; compreender inteiramente seu conteúdo para poder explicá-lo de maneira organizada com conhecimento e entusiasmo ${ }^{1,4,19}$.

Hammarling e Higham ${ }^{14}$ chamam a atenção para a possibilidade de que alguns congressistas não parem 
em frente a um pôster que foi corretamente preparado, mas o apresentador não deve se decepcionar. Gonçalves ${ }^{9}$, em 2005, descreveu que a avaliação do trabalho apresentado é geralmente verificada, principalmente, pela disponibilidade do autor em discutir o tema e a metodologia utilizada, bem como pelo interesse dos freqüentadores da sessão.

De maneira geral, as salas de painéis não devem estar distantes das de conferências; se a área de apresentação for grande o bastante, considere que uma boa audiência é assegurada ${ }^{14}$. Alguns autores ${ }^{9,24}$ são favoráveis à utilização do recurso de o apresentador distribuir cartões de visita entre os pesquisadores interessados no tema, tornando possível o marketing pessoal. Outros autores ${ }^{1,5,9}$ orientam a confecção de folder anexo no canto esquerdo superior da placa do pôster para facilitar o posterior contato dos interessados com o autor. $\mathrm{O}$ folder deverá conter tópicos como introdução, objetivo, metodologia, resultados, conclusão e identificação do autor.

É de bom senso dar uma palavra aos organizadores das conferências do evento, se desejar fazer-se notar e quiser que o trabalho seja visto como alternativa viável para uma conversa ou publicação. Isso incentiva os organizadores das conferências a dar atenção aos pesquisadores, fornecendo facilidades apropriadas para o ajuste das apresentações e incentivando participantes de conferência para atender às sessões ${ }^{14}$.

Em 2005, Zelle e cols. ${ }^{30}$ analisaram os sumários dos pôsteres registrados nos anais da $71^{\mathrm{a}}$ Reunião Anual da Academia Americana de Cirurgiões Ortopédicos, realizada no ano 2004, e encontraram $76 \%$ de discrepâncias entre os sumários enviados e os conteúdos reais dos pôsteres apresentados. O estudo demonstrou uma taxa elevada da inconsistência entre sumários escritos no manual e os pôsteres correspondentes. As mudanças foram detectadas em todas as partes dos trabalhos, incluindo os títulos (33\%), os autores $(49 \%)$, os métodos $(8 \%)$, os resultados $(30 \%)$ e as conclusões $(2 \%)$. Apesar de mudanças nas conclusões terem sido raras, os autores sugerem que os participantes de congressos não devem supor que os anais forneçam uma reflexão exata das apresentações, portanto recomendam aos congressistas visitar a seção de pôster ${ }^{30}$.

\section{Novidades}

De Simone e cols. ${ }^{6}$ consideram, em seus estudos, uma necessidade de se melhorar a qualidade e o impacto de sessões de pôster e sugerem que outros dispositivos visuais, tais como o pôster eletrônico, também chamado de pôster digital ou e-pôster, possam ser utilizados na comunicação científica. $\mathrm{O}$ estudo realizado por De
Simone e cols. ${ }^{6}$ comparou a qualidade do pôster eletrônico com comunicações de pôster tradicional. Consiste na apresentação por processo eletrônico do resumo do trabalho, utilizando o programa PowerPoint. Durante as sessões, os apresentadores falam como se fosse um pôster tradicional, porém, durante a apresentação, usam computadores, clicando em tabelas ou em figuras individuais para ampliar à tela cheia ${ }^{6,14}$.

A grande aceitação dessa nova ferramenta de comunicação é baseada principalmente na larga difusão de computadores pessoais para apresentar os dados científicos $^{6}$. Os autores concluíram que os e-pôsteres permitem apresentações detalhadas de uma base de dados por computador, são mais baratos, devendo ser usados para melhorar as comunicações originais.

\section{Conclusão}

À medida que a taxa de informação científica e técnica cresce, as conferências nacionais e internacionais buscam fornecer mecanismos para facilitar a comunicação rápida de idéias científicas com as apresentações de temas livres no formato pôster. Atualmente, este é considerado um recurso valioso para a comunicação científica, uma vez que os aspectos visuais e as explanações verbais do apresentador tornam-se uma maneira eficaz para a divulgação da pesquisa.

Pôsteres bem preparados são meios eficazes de difundir dados da pesquisa, disseminar seus resultados e estimular a discussão. Entretanto, é condição sine qua non conhecer os fundamentos de sua preparação.

A literatura sugere que o autor se faça algumas perguntas durante a produção de um painel. O que eu quero que o leitor recorde? A mensagem está clara? Os pontos importantes foram abordados? Há alguma distorção entre as ilustrações e o texto? O leitor é capaz de seguir o fluxo? Essas perguntas ajudarão o pesquisador a compreender a importância de se comunicar eficazmente.

Embora alguns pesquisadores considerem a confecção de um pôster difícil e dispendiosa, este estudo demonstrou que é possível produzi-lo com planejamento cuidadoso e materiais acessíveis. Concluiu-se que, para alguns investigadores e participantes de conferências, os pôsteres podem fornecer uma atmosfera mais relaxada durante a troca de informações. A apresentação do trabalho científico no formato pôster é válida não somente pelo que se aprende, mas também pelos contatos efetuados.

O esforço dos pesquisadores para apresentar os seus trabalhos na forma pôster será recompensado com a demonstração de trabalhos de alto índice técnico e de efeito visual agradável. 


\section{Referências}

1. BUTZ AM, KOHR L, JONES D: Developing a successful poster presentation. J Pediatr Health Care 18:45-8, 2004.

2. CAMPBELL RS: How to present, summarize, and defend your poster at the meeting. Respir Care 49:1217-21, 2004.

3. CLEARY M, WALTER G: Apportioning our time and energy: oral presentation, poster, journal article or other? Int J Ment Health Nurs 13:204-7, 2004.

4. CROOKS DL, KILPATRICK M: In the eye of the beholder: making the most of poster presentations-Part 2. Can Oncol Nurs J 8:154-9, 1998.

5. DAY RA: Como escrever e publicar um artigo científico. Ed. 5. São Paulo, Santos Livraria e Editora, 2001. pp 189-92.

6. DE SIMONE R, RODRIAN J, OSSWALD B, SACK FU, DE SIMONE E, HAGL S: Initial experience with a new communication tool: the 'Digital Interactive Poster Presentation'. Eur J Cardiothorac Surg 19:953-5, 2001.

7. DURBIN CG: Effective use of tables and figures in abstracts, presentations, and papers. Respir Care 49:1233-7, 2004.

8. FRANZOLIM IR: Como escrever melhor e obter bons resultados. São Paulo, Madras, 2004. pp 23-6.

9. GONÇALVES HA: Manual de resumos e comunicações científicas. São Paulo, Avercamp, 2005. pp 82-90.

10. GONZÁLEZ-TORTOSA J: Estética y dinámica visual de la presentación científica. Conceptos básicos. Neurocirugía 17:148-57, 2006

11. GUSMÃO SS, SILVEIRA RL: Redação de artigo científico original. Arq Bras Neurocir (São Paulo) 18:225-9, 1999

12. GUSMÃO SS, SILVEIRA RL: Redação de resumo de tema livre para congresso médico. Arq Bras Neurocir 20:106-9, 2001.

13. HADDAD N: Metodologia e estudos em ciências da saúde: como planejar, analisar e apresentar um trabalho científico. São Paulo, Roca, 2004. pp 239-41.

14. HAMMARLING S, HIGHAM NJ: How to prepare a poster. SIAM News 29, 1996. Disponível em URL: http://www. siam.org/siamnews/general/poster.htm. Acessado em 01/05/06.

15. HILL S: History of the poster. J Biocommun 29:6-8, 2003.

16. JOHNS M: Planning and producing scientific posters. $J$ Audiov Media Med 21:13-7, 1998.
17. KARAMZADEHAM, WONG BJ, CRUMLEY RL: A cost-benefit analysis and method of creating high-quality posters for a low cost. Laryngoscope 112:21-2, 2002.

18. KEELY BR: Planning and creating effective scientific posters. J Contin Educ Nurs 35:182-5, 2004.

19. LAKATOS EM. In: MARCONI MA, LAKATOS EM (eds): Fundamentos de metodologia científica. 6. ed. São Paulo: Atlas, 2005. pp 256-7.

20. LAUZON S, GOULET C, FAUCHER B: The poster, an intelligent choice for scientific communication. Infirm Que 4:31-8, 1997.

21. MALTBY HJ, SERRELL M: The art of poster presentation. Collegian 5:36-7, 1998.

22. MOORE LW, AUGSPURGER P, KING MO, PROFFITT C: Insights on the poster preparation and presentation process. Appl Nurs Res 14:100-4, 2001.

23. PALAOGLU O: The art of scientific presentation. Acta Neurochir (Suppl) 83:105-8, 2002.

24. SECAF V: Artigo Científico. Do Desafio à Conquista. São Paulo, Reis Editorial, 2000. pp 103-7.

25. SHELLEDY DC: How to make an effective poster. Respir Care 49:1213-6, 2004.

26. SUPE AN, SAHU DR: The art and science of presentation: the poster. J Postgrad Med 46:112-5, 2000.

27. TAGGART HM, ARSLANIAN C: Creating an effective poster presentation. Orthop Nurs 19:47-9, 2000.

28. TULSKY AA, KOUIDES RW: Abstract presentations: what do SGIM presenters prefer? Society of General Internal Medicine. J Gen Intern Med 13:417-8, 1998.

29. WHITE A, WHITE L: Preparing a poster. Acupunct Med 21:23-7, 2003.

30. ZELLE BA, ZLOWODZKI M, BHANDARI M: Discrepancies between proceedings abstracts and posters at a scientific meeting. Clin Orthop Relat Res 435:245-9, 2005.

Original recebido em agosto de 2006

Aceito para publicação em abril de 2007

\section{Endereço para correspondência}

Carlos Umberto Pereira

Av. Augusto Maynard, 245/404

49015-380 - Aracaju, SE

E-mail:umberto@infonet.com.br 